Article

\title{
Pituitary Hormones (FSH, LH, PRL, and GH) Differentially Regulate AQP5 Expression in Porcine Ovarian Follicular Cells
}

\author{
Mariusz T. Skowronski ${ }^{1, *(1)}$, Patrycja Mlotkowska ${ }^{2}$, Damian Tanski ${ }^{3}{ }^{\oplus}$, Ewa Lepiarczyk $^{4}$, \\ Bartosz Kempisty ${ }^{5,6,7}$, Lukasz Jaskiewicz ${ }^{4}\left(\mathbb{D}\right.$, Chandra S. Pareek ${ }^{1,8}$ and \\ Agnieszka Skowronska 4,*(D) \\ 1 Veterinary Center, Nicolaus Copernicus University in Torun, 87-100 Torun, Poland; \\ chandra.s.pareek@gmail.com \\ 2 Department of Animal Physiology, The Kielanowski Institute of Animal Physiology and Nutrition, Polish \\ Academy of Sciences, 05-110 Jabłonna, Poland; patrycja.mlotkowska@wp.pl \\ 3 Department of Animal Anatomy and Physiology, University of Warmia and Mazury in Olsztyn, \\ 10-719 Olsztyn, Poland; damian.tanski@uwm.edu.pl \\ 4 Department of Human Physiology, School of Medicine, University of Warmia and Mazury in Olsztyn, \\ 10-752 Olsztyn, Poland; ewa.lepiarczyk@uwm.edu.pl (E.L.); lukasz.jaskiewicz@uwm.edu.pl (L.J.) \\ 5 Department of Histology and Embryology; Poznan University of Medical Sciences, 61-701 Poznan, Poland; \\ bkempisty@ump.edu.pl \\ 6 Department of Anatomy, Poznan University of Medical Sciences, 61-701 Poznan, Poland \\ 7 Department of Obstetrics and Gynecology, University Hospital and Masaryk University, \\ 60200 Brno, Czech Republic \\ 8 Interdisciplinary Center of Modern Technology, Nicolaus Copernicus University in Torun, \\ 87-100 Torun, Poland \\ * Correspondence: skowron@umk.pl (M.T.S.); agnieszka.skowronska@uwm.edu.pl (A.S.); \\ Tel.: +48-607-356-323 (M.T.S.); +48-89-524-53-34 (A.S.)
}

Received: 10 September 2019; Accepted: 30 September 2019; Published: 3 October 2019

\begin{abstract}
This study aimed to examine the effect of follicle-stimulating hormone (FSH), luteinizing hormone (LH), prolactin (PRL), and growth hormone (GH) on Aquaporin 5 (AQP5) expression in granulosa (Gc) and theca cells (Tc) from medium (MF) and large (LF) ovarian follicles of pigs. The results showed that GH significantly decreased the expression of AQP5 in Gc from MF in relation to the control. In the Gc of large follicles, PRL stimulated the expression of AQP5. However, the increased expression of AQP5 in the Tc of LF was indicated by GH and PRL in relation to the control. A significantly higher expression of the AQP5 protein in the Gc from MF and LF was indicated by FSH and PRL. In co-cultures, an increased expression of AQP5 was observed in the Gc from LF incubated with LH, PRL, and GH. A significantly increased expression of AQP5 was also observed in co-cultures of Tc from all type of follicles incubated with LH, whereas PRL stimulated the expression of AQP5 in Tc from MF. Moreover, AQP5 protein expression increased in the co-culture isolated from MF and LF after treatment with FSH, LH, PRL, and GH. AQP5 immunoreactivity was observed in the cytoplasm, mainly in the perinuclear region and endosomes, as well as in the cell membranes of Gc and Tc from the LF and MF.
\end{abstract}

Keywords: Aquaporin 5; gene and protein expression; ovarian cells; in vitro study; pig

\section{Introduction}

Fluid transport across cellular barriers in biological tissues results from water transport driven by osmotic gradients or hydrostatic pressure differences. The aquaporins (AQPs) are a family of small hydrophobic intra-membranous proteins $(25-34 \mathrm{kDa})$, functioning as cell membrane water 
channels facilitating water and small neutral solute transport across a variety of biological membranes. Transcellular water flow is dependent on the permeability of the plasma membrane to water molecules $[1,2]$.

AQPs are expressed in a wide range of tissues, often spatially located within a certain region of the cell. This enables them to play a central role in physiological processes in the flow of water through those tissues, which typically triggers the cell volume regulation mechanism. The involvement of these small proteins in cell adhesion, migration, proliferation, and cell differentiation has also been defined [3]. The important role of AQPs was discovered following the observation of a mouse model with silenced genes (Aqp-null mice), e.g., the involvement of AQPs in cell migration (AQP1) [4], fat metabolism (AQP7) [5] and glucose metabolism (AQP9) [6]. The expression of aquaporins varies, depending on the tissue. Furthermore, any one cell may possess several isoforms, often located at opposite poles of the cell, in the apical membranes and basolateral membranes. There is now an emerging consensus that the rapid and reversible translocation of AQPs from intracellular vesicles to the plasma membrane is trigged by a range of stimuli. For example, as a result of stimulation of the $\alpha_{1}$-adrenergic receptor, AQP5 translocates from intracellular membranes to the apical membranes of rat parotid gland cells [7].

Twelve AQP isoforms are expressed in the mammalian reproductive system and play very important roles in maintaining water homeostasis in reproductive cells, and their dysfunction can lead to impaired fertility. Studies on the human uterus have demonstrated the mRNA expression of $A Q P 1$, $2,3,4,5,7,8,9$, and 11 in chorion, amnion, and the placenta, but not $A Q P 2[8,9]$. Very recently, Klein et al. [10] demonstrated the uterine mRNA expression of 12 different AQP subtypes, while Western blot analysis confirmed the protein expression of AQP0, 2, and 5. The presence of AQPs was found in plasma membranes of all animal cells, but the mechanism of their action and the transcriptional level (in the mRNA and protein) are unclear. Transport and water homeostasis in the ovary, oviduct, uterus, placenta, and fetal membranes is crucial for the maintenance of a normal reproductive function, oocyte development, embryo implantation, and fetal growth. Depending on the physiological status of the reproductive system (phase of the cycle, implantation, placentation, and labor), there is a periodic agitation or silencing of many genes in their structures. The following question then arises: what is the role of hormones in the regulation and expression of $\mathrm{AQP}$ genes and proteins?

The first publications concerning the role of steroid hormones (estradiol, $\mathrm{E}_{2}$, and progesterone, $\mathrm{P}_{4}$ ) in the regulation of AQP1 and 5 expression in the uterine tissue of mice and rats showed their different effects. A direct action of $\mathrm{E}_{2}$ on AQP5 expression in a mouse uterus was found [11]. Then, other authors demonstrated that the administration of $\mathrm{P}_{4}$ and/or $\mathrm{E}_{2}$ regulates AQP1 and AQP5 expression in the uterus of ovariectomized rats [12]. However, in ovariectomized mice, the same treatment did not reveal similar changes. It was not until the earlier administration of $\mathrm{P}_{4}$, and then the administration of $E_{2}$, that $A Q P 5$ expression was induced [13]. It was also demonstrated that after $\mathrm{E}_{2}$ treatment, $A Q P 1 \mathrm{mRNA}$ expression increased in mice myometrium, but not the protein level. In turn, by applying immunocytochemistry and immunoprecipitation techniques, other researchers demonstrated a significant effect of estrogens on the localization of AQP1 in mice myometrium, without any effect on AQP5 expression [14]. Furthermore, the expression of human endometrial AQP2 occurs in the menstrual cycle because of the estrogen response element in the promoter region of the AQP2 gene. AQP2 is involved in water transport in the human endometrium and might play a role in the cyclic changes of the endometrium, suggesting a role for AQP2 in implantation, edema, and/or menstruation [15,16]. Ducza and others [17] demonstrated the effect of oxytocin on AQP5 expression in a rat uterus during pregnancy. Recently, this research group indicated an influence of female sexual hormones on the expression of AQP5 in a late-pregnant rat uterus [18,19].

Reports on AQP expression in the ovary are not as numerous as in the uterus. Experiments have shown that AQPs are involved in the process of pig folliculogenesis [20], as well as in the creation of the vesicle cavity (antrum) in rodents and humans [21,22]. McConnell et al. [23] showed that the rapid flow of water to rat follicle cavities mainly occurs via the transmembrane pathway in granulosa cells $(\mathrm{Gc})$, probably involving AQP7, AQP8, and AQP9. Recently, studies by Starowicz et al. [24] showed the presence of AQP5 in preovulatory ovarian follicles and its role in the process of cumulus oophorus expansion. 
Rodges and Irving-Rodgers' report indicated that the production of hyaluronan by Gc generates an osmotic gradient that causes fluid to move from the theca cells (Tc) to the Gc, facilitating the transcellular flow of water [25].

Inspiration for this study came from the earlier results obtained from pigs. These results suggest that functional and distinctive collaboration exists among diverse AQPs in a pig's ovary, oviduct, and uterus during the estrous cycle and early pregnancy $[19,26,27]$. We observed the specific pattern of expression and established an anatomical basis for examined AQPs, which indicates that they play important functions in the regulation of water movement to maintain adequate hydration and the regeneration ability of the reproductive tract. Recently, our study found that the follicle-stimulating hormone (FSH), luteinizing hormone (LH), prolactin (PRL), and growth hormone (GH) regulated AQP1 expression in the ovarian follicular cells of pigs [28].

Hence, the aim of this study was to establish whether the above mentioned biological factors also participate in the regulation of mRNA and protein expression of AQP5 in porcine follicular cells.

\section{Results}

2.1. The Effects of FSH, LH, PRL, and GH on AQP5 mRNA Expression in Gc and Tc Cells from the Medium $(M F)$ and Large (LF) Follicles

AQP5 mRNA expression significantly decreased in the Gc cells isolated from medium follicles after a $24 \mathrm{~h}$ culture with GH compared to the control ( $p<0.05$; Figure 1A). PRL increased AQP5 mRNA expression in the Gc cells obtained from large follicles $(p<0.05$; Figure 1B). In the Tc obtained from large follicles, PRL and GH significantly increased AQP5 mRNA expression $(p<0.05$; Figure 1D). Other treatments did not affect AQP5 mRNA expression in both cells at the examined time point in comparison to the control group (Figure 1A-D).
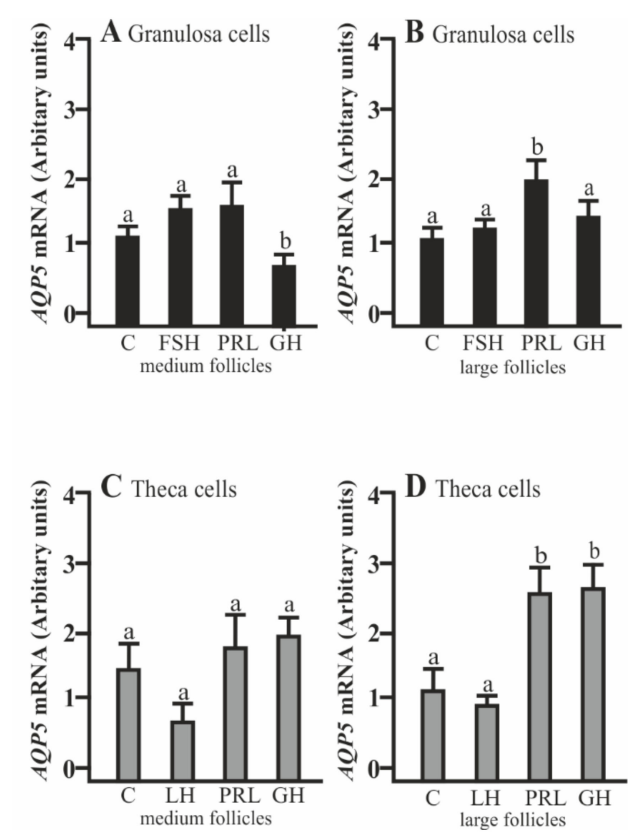

Figure 1. The changes in the expression of Aquaporin 5 (AQP5) mRNA in porcine granulosa (Gc) and theca cells $(\mathrm{Tc})$ obtained from medium (MF) and large (LF) follicles after $24 \mathrm{~h}$ incubation in the absence (C) or presence of follicle-stimulating hormone (FSH), luteinizing hormone (LH), prolactin (PRL), and growth hormone $(\mathrm{GH})$. The samples were subjected to real-time qPCR analysis and normalized to the expression of Glyceraldehyde 3-phosphate dehydrogenase (GAPDH) and Cyclophylin A (PPIA), $(\mathbf{A}, \mathbf{B})$ in the $\mathrm{Gc}$ and $(\mathbf{C}, \mathbf{D})$ Tc. Values are expressed as means \pm S.E.M from five separate experiments, each performed in triplicate ( $p<0.05$ compared with controls). Statistically significant differences between treatments are indicated by different letters $(\mathrm{a}, \mathrm{b})$. $\mathrm{C}$ : control. 


\subsection{The Effects of FSH, LH, PRL, and GH on AQP5 Protein Expression in the Gc and Tc Cells from MF and LF}

SDS-PAGE and Western blot analysis revealed that FSH and PRL increased the AQP5 protein expression in porcine GC cultured for $24 \mathrm{~h}$ obtained from medium and large follicles $(p<0.05$; Figure $2 \mathrm{~A}, \mathrm{~B}$ ) in comparison to the control. AQP5 protein was detectable in Tc isolated from medium and large porcine follicles, but the tested factors did not affect the AQP5 expression.

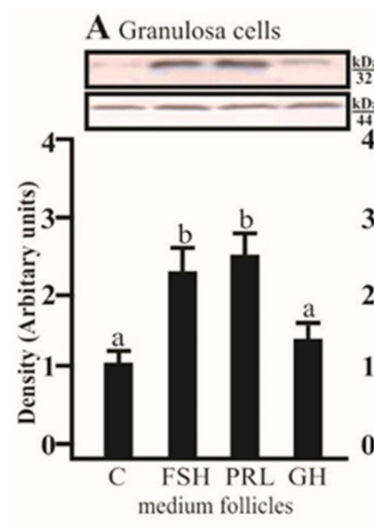

B Granulosa cells
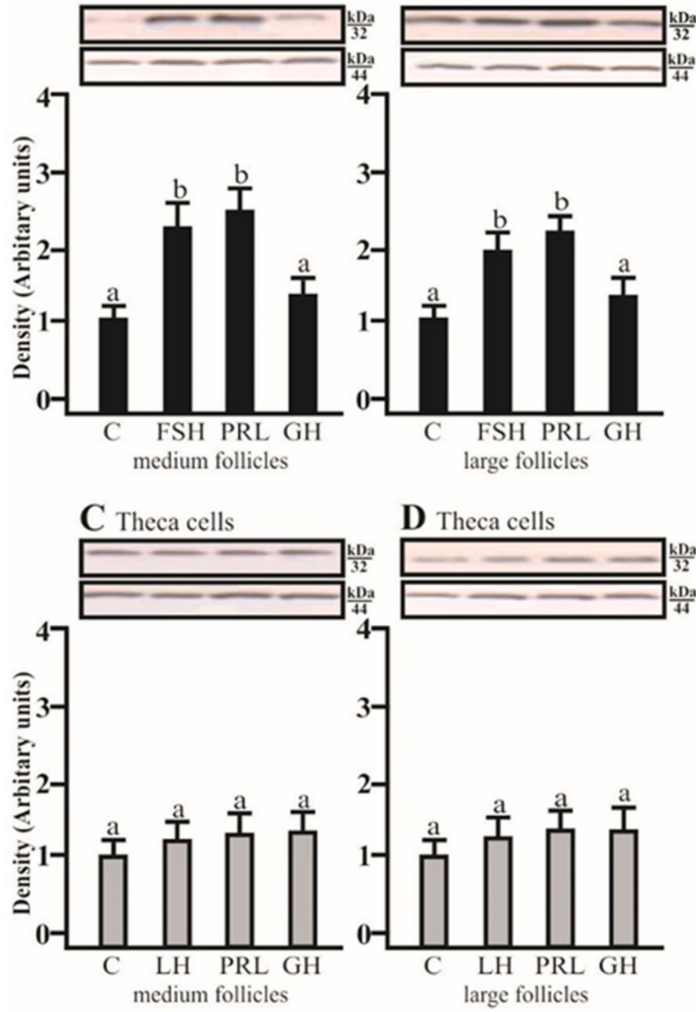

D Theca cells

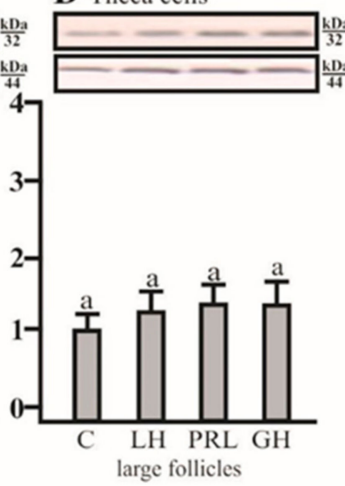

Figure 2. The changes in the expression of AQP5 (kDa 32) protein in porcine Gc and Tc obtained from MF and LF after $24 \mathrm{~h}$ incubation in the absence (C) or presence of follicle-stimulating hormone (FSH), luteinizing hormone $(\mathrm{LH})$, prolactin $(\mathrm{PRL})$, and growth hormone $(\mathrm{GH})$. The samples were subjected to Western blot analysis and normalized to the expression of $\beta$-actin (kDa 44), (A,B) in the Gc and $(\mathbf{C}, \mathbf{D})$ Tc. Values are expressed as means \pm S.E.M from five separate experiments, each performed in triplicate ( $p<0.05$ compared with controls). Statistically significant differences between treatments are indicated by different letters $(\mathrm{a}, \mathrm{b})$. C: control.

2.3. The Effects of FSH, LH, PRL, and GH on AQP5 mRNA Expression in the Co-Culture of Gc and Tc Cells from $M F$ and $L F$

The co-culturing of Gc with theca cells from the large follicles in the presence of LH, PRL, and GH significantly increased AQP5 mRNA expression compared to the respective control ( $p<0.05$; Figure 3B). The addition of LH and PRL produced a significant increase in AQP5 mRNA expression in the Tc coculture with granulosa cells of medium follicles $(p<0.05$; Figure 3C). A stimulatory effect on AQP5 mRNA was observed in the Tc in the presence of LH $(p<0.05$; Figure 3D). Other treatments did not affect AQP5 mRNA expression in both cells at the examined time point in comparison to the control group (Figure 3A-D). 

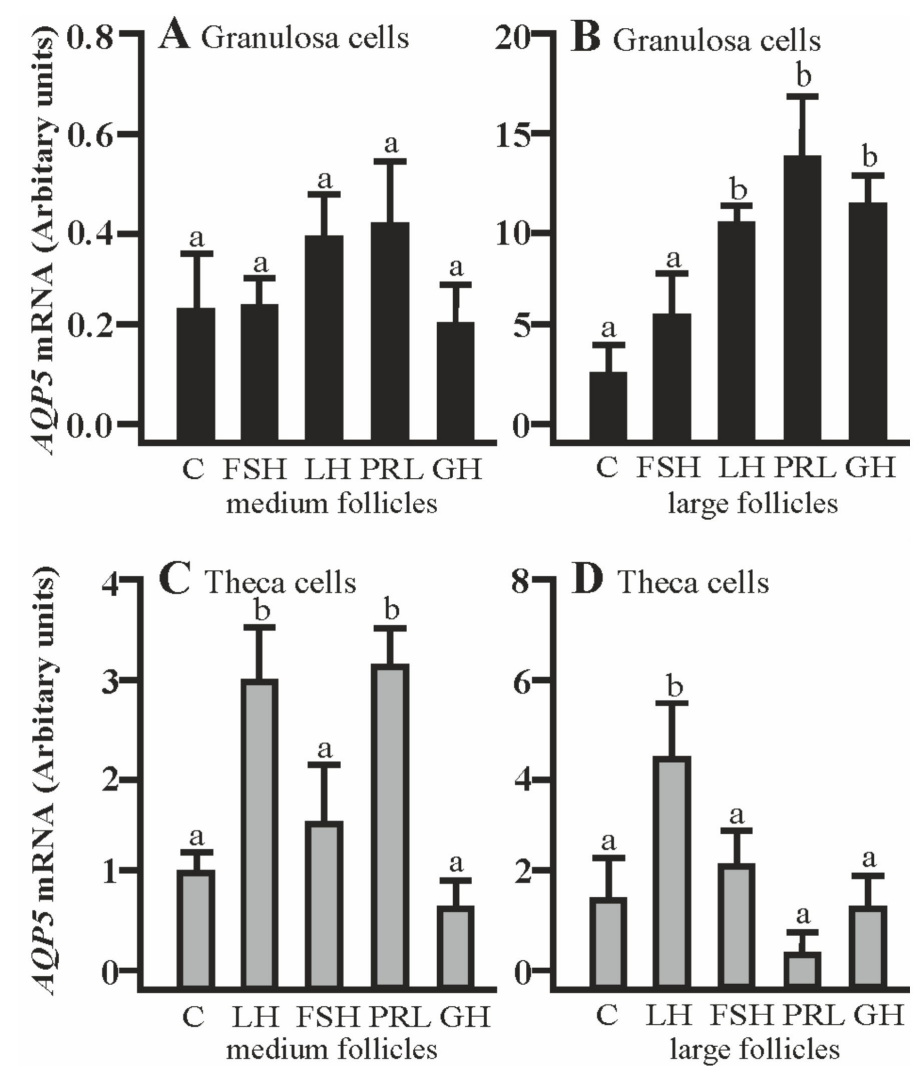

Figure 3. The changes in the expression of AQP5 mRNA in porcine Gc and Tc obtained from MF and LF after $24 \mathrm{~h}$ co-culture of these cells in the absence (C) or presence of follicle-stimulating hormone (FSH), luteinizing hormone $(\mathrm{LH})$, prolactin (PRL), and growth hormone $(\mathrm{GH})$. The samples were subjected to real-time qPCR analysis and normalized to the expression of GAPDH and PPIA, (A,B) in the Gc and $($ C,D) Tc. Values are expressed as means \pm S.E.M from five separate experiments, each performed in triplicate $(p<0.05$ compared with controls). Statistically significant differences between treatments are indicated by different letters (a,b). C: control.

2.4. The Effects of FSH, LH, PRL, and GH on AQP5 Protein Expression in the Co-Culture of Gc and Tc Cells from $M F$ and $L F$

AQP5 protein expression significantly increased in the co-culture of Gc with Tc isolated from medium and large follicles after treatment with FSH, LH, PRL, and GH, respectively $(p<0.05$; Figure 4A,B). In the co-culture of Tc with Gc obtained from medium follicles, AQP5 protein expression significantly increased with FSH, LH, PRL, and GH ( $p<0.05$; Figure $4 \mathrm{C})$. In large follicles, this effect was only observed in the presence of GH ( $p<0.05$; Figure 4D). 


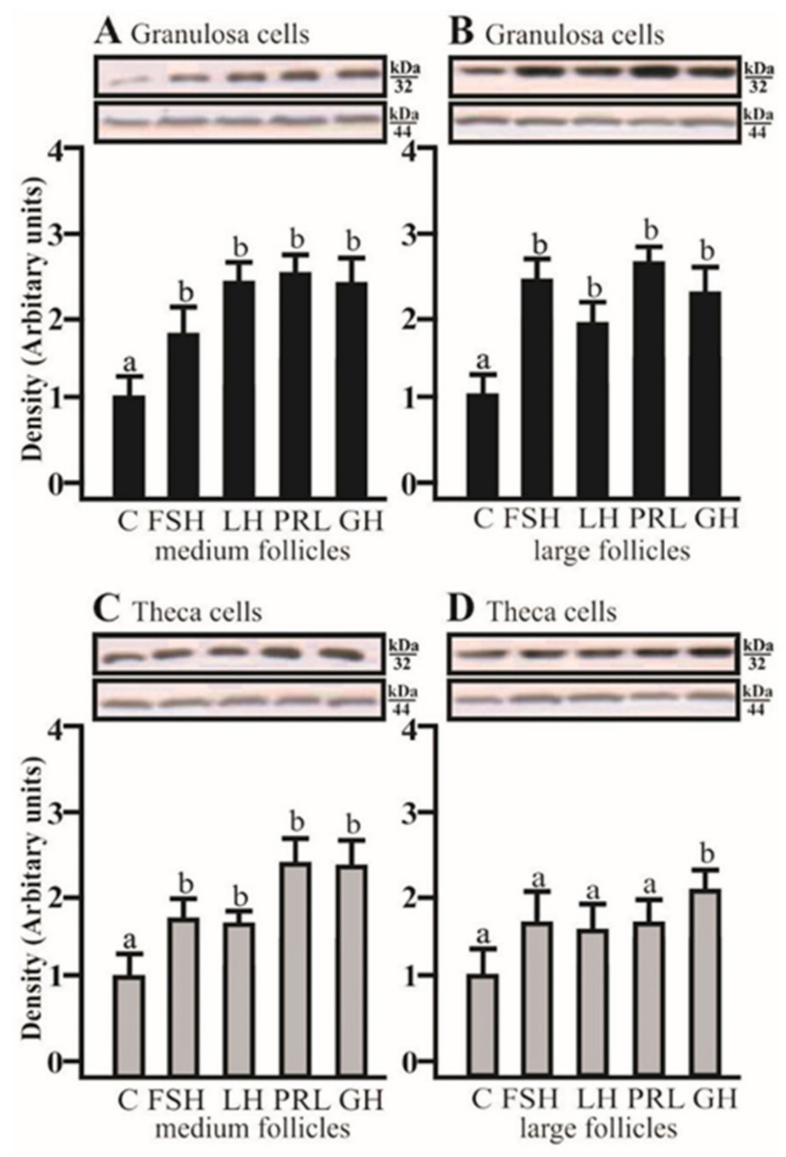

Figure 4. The changes in the expression of AQP5 $(\mathrm{kDa} 32)$ protein in porcine Gc and Tc obtained from MF and LF after $24 \mathrm{~h}$ co-culture of these cells in the absence (C) or presence of follicle-stimulating hormone (FSH), luteinizing hormone (LH), prolactin (PRL), and growth hormone (GH). The samples were subjected to Western blot analysis and normalized to the expression of $\beta$-actin (kDa 44), (A,B) in the Gc and (C,D) Tc. Values are expressed as means \pm S.E.M from five separate experiments, each performed in triplicate ( $p<0.05$ compared with controls). Statistically significant differences between treatments are indicated by different letters $(a, b)$. C: control.

2.5. The Effects of FSH, LH, PRL, and GH on AQP5 Protein Expression in the Culture of Gc and Tc Cells from $M F$ and $L F$

Immunofluorescence found that AQP5 protein was localized in the cytoplasm, mainly in the perinuclear region and endosomes, and weak labeling was observed in the cell membranes of Gc (Figure 5A-D) and Tc (Figure 6A-D) cells from the LF, as well as Gc (Figure 5E-H) and Tc (Figure 6E-H) cells from the MF. There was no effect on the distribution in these cells of AQP5 protein after $24 \mathrm{~h}$ treatment with FSH, LH, PRL, and GH compared to the controls (Figures 5 and 6). 


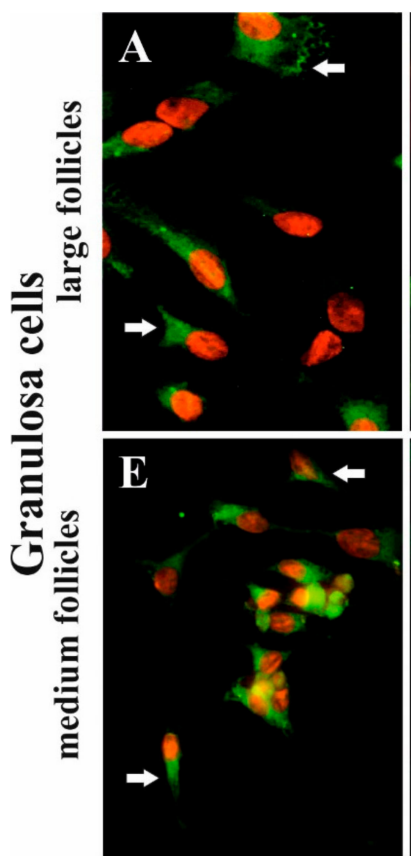

C
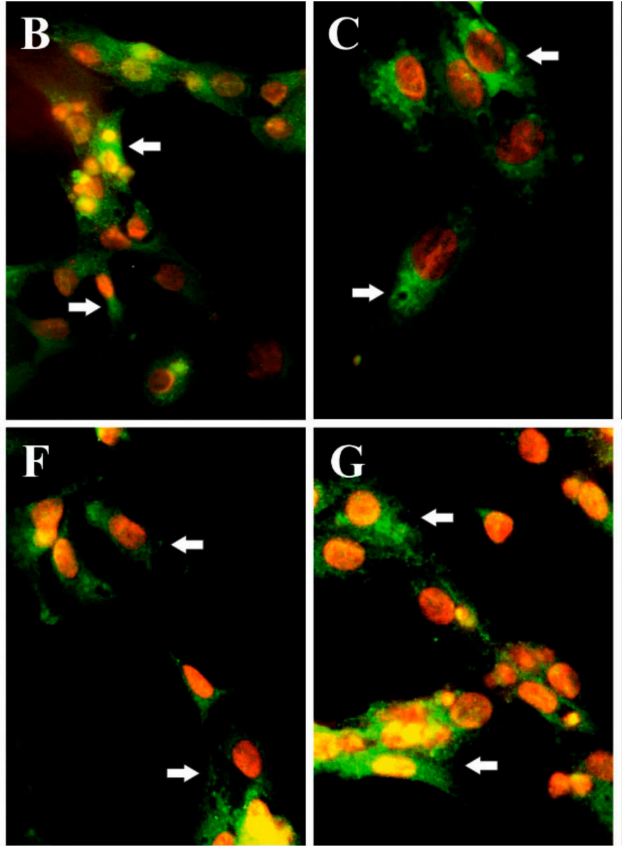

FSH

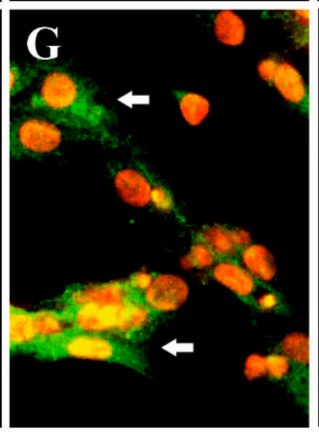

PRL

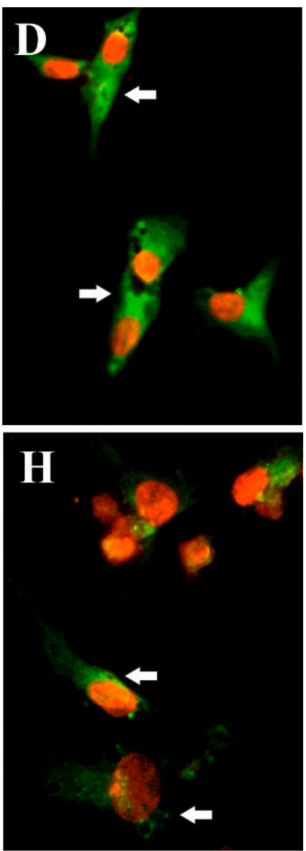

GH

Figure 5. The influence of FSH, PRL, and GH on the subcellular distribution of AQP5 in the Gc of porcine ovarian follicles. After being exposed to FSH (B,F), PRL $(\mathbf{C}, \mathbf{G})$, and GH (D,H) for $24 \mathrm{~h}, \mathrm{Gc}$ were incubated with anti-AQP5 antibody and visualized with Alexa-488 (in green). Nuclei were stained with propidium iodide (in red). Arrow indicates the localization of AQP5 in the cells. The data are representative of five individual experiments, each carried out in duplicate. C: control $(\mathbf{A}, \mathbf{E})$; magnification of $600 \times$.

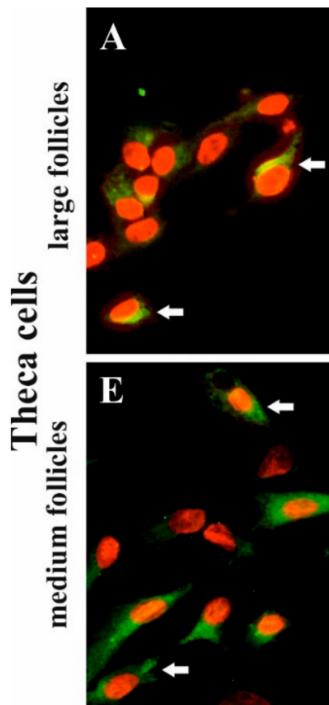

C

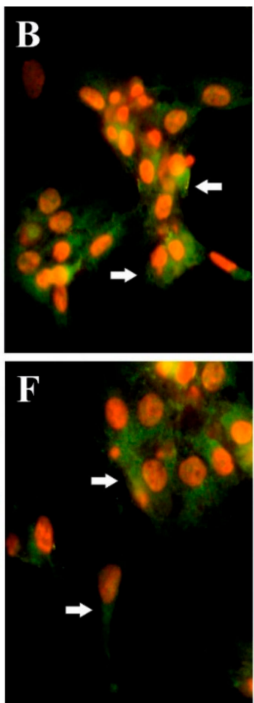

LH
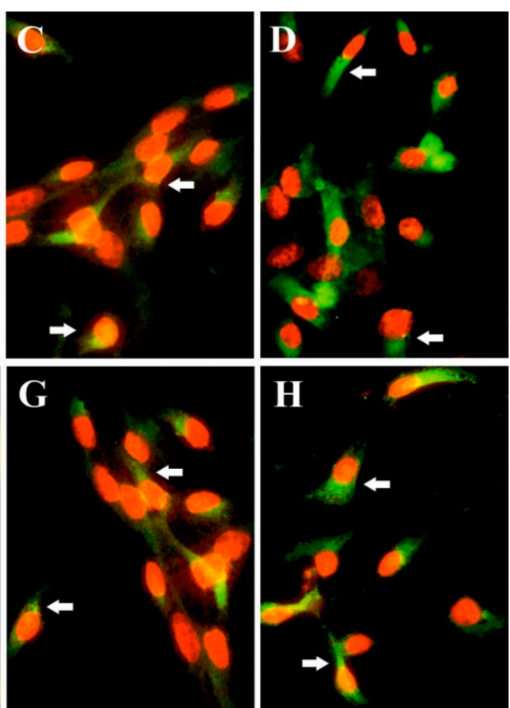

PRL

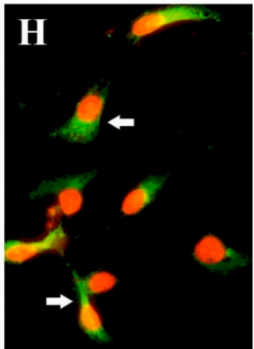

GH

Figure 6. The influence of LH, PRL, and GH on the subcellular distribution of AQP5 in Tc of porcine ovarian follicles. After being exposed to LH (B,F), PRL $(\mathbf{C}, \mathbf{G})$, and GH (D,H) for $24 \mathrm{~h}$, Tc were incubated with anti-AQP5 antibody and visualized with Alexa-488 (in green). Nuclei were stained with propidium iodide (in red). Arrow indicates the localization of AQP5 in the cells. The data are representative of five individual experiments, each carried out in duplicate. C: control (A,E); magnification of 600×. 


\section{Discussion}

Inspiration for this study came from the earlier results obtained from the pig [28]. The study found that follicle-stimulating hormone (FSH), luteinizing hormone (LH), prolactin (PRL), and growth hormone $(\mathrm{GH})$ regulated AQP1 expression in the ovarian follicular cells of pigs. The present results suggest that AQP5 can also be regulated by FSH, LH, PRL, and GH.

In previous research [28] we found a stimulatory effect of FSH and LH on AQP1 mRNA and protein expression in the Gc ant Tc of pig medium and large ovarian follicles and co-cultures of these cells. In the present research, AQP5 was mainly submitted to the regulatory effect of FSH and LH, since these hormones markedly increased AQP5 mRNA and protein expression in Gc and Tc, as well as in co-cultures of the cells. Therefore, it may be assumed that FSH and LH exert their effect on porcine follicles by influencing the mRNA and protein expression of AQP1 and AQP5.

Previous studies reported an effect of steroid hormones on AQP expression in the female reproductive system [14,23]. Estrogens up-regulated $A Q P 2$ and $A Q P 5$ by the promoter regions, as shown in the human and rodent uterus $[11,16]$. These hormones stimulate follicular cell proliferation and, together with $\mathrm{FSH}$, initiate the formation of $\mathrm{LH}$ receptors in granulosa cells, as well as progesterone and androgen production in theca cells $[29,30]$. Our previous papers presented the influence of steroid hormones on AQPs in the female reproductive system [31,32]. Others have presented very interesting results on transgenic mice deficient in AQP proteins due to different reproductive phenomena [33-36]. Our previous studies [37] demonstrated AQP5 and AQP9 in porcine granulosa cells and AQP1 in theca cells. Zhu et al. [38] found the mRNA expression of AQP1, 3, 4, 5, 6, 7, 8, 9, and 11 in a pig placenta on day 25 of gestation. The authors also identified AQP1, 3, 5, and 9 protein expression in the placenta, uterine endometrium, and porcine trophectoderm cell lines.

Ovarian follicle growth, differentiation, and steroidogenic activity are controlled by many factors, of which FSH, LH, PRL, and oxytocin are the most important [39]. Moreover, the authors have emphasized that the growth of follicles and steroidogenesis is controlled by the interaction between insulin-like growth factors (IGF-S) and gonadotrophins. Attention has also been focused on GH, which affects the follicular function by the hypothalamic-pituitary axis or acting directly on the ovary. The direct effects of GH on steroidogenesis in porcine granulosa cells have been found [40]. Moreover, Kolodziejczyk et al. [41] found that Gc and Tc produce IGF-I and showed the effect on proliferation of the cells. Growth hormone, $\mathrm{LH}$, and sex steroids are necessary for proper ovarian angiogenesis due to their influence on local factors, mainly the vascular endothelial growth factor $\mathrm{A}$ (VEGF-A) [42]. Research involving a pRNA-H1.1 vector containing the short hairpin RNA (shRNA) targeting AQP5 mRNA expression in human umbilical vein endothelial cells (HUVECs) found that the $A Q P 5$-silenced HUVECs acquired decreased proliferation, migration, and the tube formation ability. Furthermore, the expression and secretion of VEGF-A in colorectal cancer cells were downregulated by $A Q P 5$ shRNA [43].

We recently demonstrated a stimulatory effect of PRL on AQP1 protein expression in the co-cultures of Gc and Ts of medium and large follicles [28]. GH increased the expression of AQP1 protein in Gc isolated from large follicles. Furthermore, the expression of $A Q P 1$ mRNA was significantly higher under the influence of GH in co-cultures of Gc of large follicles, as well as Tc of medium follicles. The present study found that AQP5 mRNA expression decreased in the Gc from medium follicles with GH. PRL increased AQP5 mRNA expression in the Gc in large follicles, as well as PRL and GH did in the Tc. Protein analysis revealed that PRL increased AQP5 expression in Gc obtained from medium and large follicles. The co-culturing of the Gc and Tc cells from the large follicles in the presence of PRL and GH increased AQP5 mRNA expression. The addition of PRL produced an increase in AQP5 mRNA expression in the co-culture of cells of medium follicles. AQP5 protein expression significantly increased in the co-culture of cells isolated from medium and large follicles after treatment with PRL and GH. In the co-culture of these cells obtained from medium follicles, AQP5 protein expression significantly increased with PRL and GH in turn, in large follicles, and this effect was only observed in 
the presence of GH. Other research found the influence of osmoregulatory hormones such PRL, GH, and cortisol on AQP3 expression in the gill epithelium of Mozambique tilapia [44].

Steroid and protein hormones are produced by follicles, which, by auto- and paracrine paths, affect ovarian follicular cell functions. In the present experiment, disparity between the level of mRNA transcripts and their corresponding protein was observed. Studies frequently report that cellular protein concentrations are not strongly correlated with the abundance of their corresponding mRNAs. We have observed this disparity in our study for the tested AQPs. Recent reports indicate that only $40 \%$ of the variation in protein levels can be explained by mRNA, and this may also result from the differentiated stability of mRNAs/and or proteins. It is also noteworthy that the processes of transcription and translation are not equally efficient [45]. A significant role in these processes is dependent on miRNA, and their sequences might be complementary to one or several molecules of mRNA. Recent estimates suggest that between $30 \%$ and $50 \%$ of the genes may be regulated by miRNAs.

Our recent study on a swelling assay using an AQP blocker found the presence of AQPs in Gc and Tc [28]. The increase in volume of Gc of medium and large follicles in hypotonic conditions after treatment with FSH, PRL, and GH was higher compared to the Tc of medium and large follicles under the same osmotic conditions with LH, PRL, and GH. It is likely that Gc have more AQP isoforms in the cell membranes than the Tc, which is in agreement with the present data on separated granulosa and theca cells (Figure 2).

AQP5 expression was also confirmed by immunofluorescence analysis. AQP5 was mainly localized in the perinuclear part of the cytoplasm and endosomes, and weak labeling was observed in the cell membranes of the pig Gc and Tc from MF and LF. In previous experiments, we found a similar subcellular distribution of AQP1 to AQP5 in these cells [28]. Several studies have shown that there is a decoupling of AQP1 and AQP5, suggesting that other factors need to be considered to study the hormones that regulate one or the other aquaporins. This is seen in conditions like stimulation by $\mathrm{P}_{4}$, $\mathrm{E}_{2}$, arachidonic acid (AA), oxytocin, cyclic adenosine monophosphate (cAMP), or forskolin (FSK) in pig uterus cells during early pregnancy [31,32]. Under the control condition, AQP1 was associated with the plasma membranes of endothelial cells, but AQP5 was mainly localized in the apical membranes of uterine epithelial cells. However, after treatment with $\mathrm{P}_{4}, \mathrm{E}_{2}, \mathrm{AA}, \mathrm{cAMP}$, or FSK, AQP1 localization did not change, but AQP5 labeling additionally appeared in the basolateral membranes of epithelial cells. In other experiments, the immunofluorescence of AQP7, AQP8, and AQP9 staining showed wide localization in cytotopes of a dog's normal testis in either the tubular or interstitial partitions. In contrast, in the cryptic testis, these AQPs were only distributed in the interstitial partition of Leydig cells [46]. Recently, AQP5 was described as participating in protein-protein interactions, controlling the AQP2 isoform in kidneys [47]. There is much evidence suggesting the importance of AQP5 upregulation in tumor cell proliferation [48]. Moreover, Madeira et al. [49] have also demonstrated AQP5 as a factor implicated in adipocyte differentiation.

Based on our previous and present experiments, it might be concluded that AQP1 and AQP5 play important roles in maintaining water homeostasis in the ovarian cells of the pig. There is limited research on AQP expression in the reproductive tract of the pig, so the present research has provided some novel insights into the regulation of AQP5 by gonadotrophins, PRL, and GH in the Gc and Tc of porcine ovarian follicles. Folliculogenesis, ovulation, and corpus luteum formation and maintenance are processes that are critically dependent on appropriated water homeostasis, which may be established by the regulation of AQP5 expression by these hormones.

\section{Materials and Methods}

All experiments were performed in accordance with the Animal Ethics Committee (AEC approval No. 66/2010 DTN, 15 June 2010, University of Warmia and Mazury in Olsztyn, Poland). Tissue samples were recovered from mature cross-bred gilts (Large White $\times$ Polish Landrace) aged 7-8 months $(n=$ 20 ), with an average weight of $90-110 \mathrm{~kg}$, in a local slaughterhouse (Biskupiec, Poland). Ovaries were separated from all of the gilts and were then stored on ice and transported in cold-buffered physiological 
saline (PBS) supplemented with gentamycin and nystatin. The morphology of the ovaries has previously been evaluated [50]. The follicles were divided into two groups based on size: medium follicles (6-8 $\mathrm{mm}$ diameter) and large, pre-ovulatory follicles $(9-12 \mathrm{~mm})$.

\subsection{Cell Cultures and Experimental Design}

Granulosa and Tc were subsequently prepared according to the technique previously described [51] using a modification [52]. All stages of experiments were performed in sterile conditions. The total number of follicles ( $n=10-12)$ for each group was used to obtain separated Gc and Tc. Using a pair of fine forceps, theca interna/granulosa were separated from external layers of the follicular wall. Gc were scrubbed from the follicular wall with round-tipped ophthalmologic tweezers and rinsed off by intensive pipetting $(10 \mathrm{~s})$ and a supernatant containing Gc was decanted. After isolation, Gc were rinsed in M199 medium with 5\% bovine serum albumin (BSA) and centrifuged $\left(180 \times g, 10 \mathrm{~min}, 20^{\circ} \mathrm{C}\right)$. Then, the cell pellet was treated with a red blood cell lysing buffer, as described by [28], and the Gc were re-suspended in M199 supplemented with 5\% BSA and antibiotics and counted in Burker's chamber. Cell viability was determined by trypan blue dye exclusion and was always greater than $90 \%$. The Tc were mechanically separated from the underlying theca externa cell layer. Tc were washed with PBS, and exposed to trypsinization with 6-7 mL, $0.25 \%$ trypsin in PBS for $10 \mathrm{~min}$ at $37^{\circ} \mathrm{C}$. The cells were filtered through a nylon mesh. Finally, the cells were centrifuged and re-suspended in M199/BSA and antibiotics.

Experiment 1 was conducted to determine the effects of FSH, LH, PRL, and GH on the AQP5 mRNA expression in Gc and Tc cells. Incubation medium was M199 medium (Sigma, St. Louis, MO, USA) containing nystatin $(120 \mathrm{U} / \mathrm{mL})$ (Sigma) and gentamicin $(0.05 \mathrm{mg} / \mathrm{mL})$ (Krka, Novo Mesto, Slovenia). Aliquots of Gc were initially cultured in 1/12-well plates (Sarstedt, Equimed, Nümbrecht, Germany) with $1.0 \times 10^{6}$ cells per well and Tc with $2.5 \times 10^{5}$ cells per well without test compounds for $48-72 \mathrm{~h}$, to allow cell attachment to 11 of the 16 wells $\left(37^{\circ} \mathrm{C}, 2 \%\right.$ BSA, $10 \%$ fetal calf serum (FCS), $95 \%$ air $/ 5 \%$ $\left.\mathrm{CO}_{2}\right)$ [30]. Following $48-72 \mathrm{~h}$ of attachment, cells were cultured with treatments $\left(37^{\circ} \mathrm{C}, 2 \% \mathrm{BSA}, 5 \%\right.$ FCS, $95 \%$ air $/ 5 \% \mathrm{CO}_{2}$ ) for the next $24 \mathrm{~h}$, and $1.0 \mathrm{~mL}$ fresh M199/FCS alone was added to the control cultures, while FSH, LH, PRL, and GH were added to the experimental cultures at a concentration of $100 \mathrm{ng} / \mathrm{mL}$ (Sigma). When the experiments were terminated, the adherent cells were washed with PBS and then harvested and stored $\left(-80^{\circ} \mathrm{C}\right)$ for mRNA expression analysis.

Experiment 2 was conducted to determine the effects of FSH, LH, PRL, and GH on the AQP5 protein expression in Gc and Tc cells. Cultivations were conducted according to the procedure described above. Each treatment was conducted in four wells and each experiment was repeated three times. When the experiments were terminated, the cells $\left(-80^{\circ} \mathrm{C}\right)$ were collected and stored until all assays were completed for protein expression.

Experiment 3 was conducted for co-culture experiments to demonstrate the effects of FSH, LH, PRL, and GH on the AQP5 mRNA expression in Gc and Tc cells. For co-culture experiments, viable Gc and Tc were inoculated at a concentration of $2 \times 10^{6}$ and $0.5 \times 10^{6}$ cells/well, respectively, in tissue culture plates, which reflects typical ratios, as observed in vivo and described previously [31]. The media and incubation conditions with experimental factors were as described above. When the experiments were terminated, the cells $\left(-80^{\circ} \mathrm{C}\right)$ were collected and stored until all assays were completed for mRNA expression.

Experiment 4 was conducted for co-culture experiments to demonstrate the effects of $\mathrm{FSH}, \mathrm{LH}$, $\mathrm{PRL}$, and GH on the AQP5 protein expression in Gc and Tc cells. For co-culture experiments, viable Gc and Tc were inoculated at a concentration of $2 \times 10^{6}$ and $0.5 \times 10^{6}$ cells/well, respectively, in tissue culture plates, which reflects typical ratios, as observed in vivo and described previously [28]. The media and incubation conditions with experimental factors were as described above. When the experiments were terminated, the cells $\left(-80^{\circ} \mathrm{C}\right)$ were collected and stored until all assays were completed for protein expression.

Experiment 5 was conducted to demonstrate the subcellular distribution of AQP5 protein in the Gc and Tc cells. Cells were isolated and cultured on Mini Cell slides (Merck Millipore, Burlington, MA, USA). Aliquots of Gc and Tc were $1.0 \times 10^{5}$ cells per well/500 $\mu \mathrm{L}$ medium. The cells were cultured with 
treatments as described above (M199, 2\% BSA, 5\% FCS, 95\% air $/ 5 \% \mathrm{CO}_{2}$ ) for the next $24 \mathrm{~h}$. When the experiments were terminated, the cells were prepared for immunofluorescence.

\subsection{RNA Extraction and Real-Time $q P C R$}

Total RNA was isolated from Gc and Tc with the Total RNA kit (A\&A Biotechnology, Gdynia, Poland), following the manufacturer's recommendations, and quantified spectrophotometrically. The integrity of the product was confirmed on 1.5\% agarose gel. Reverse transcription (RT) was performed using an Enhanced Avian HS RT-PCR Kit (Sigma Aldrich, St. Louis, MO, USA), and a mix of deoxynucleotides (dNTPs), and random hexamers as primers. The RT product was kept frozen at $-20{ }^{\circ} \mathrm{C}$ for PCR analysis. Quantitative Real-Time PCR was used to establish dynamic changes in AQP5 mRNA expression. The following primer sequences were used [28,32]: AQP5 forward CTATGAGTCCGAGGAGGATT, AQP5 reverse GCTTCGCTGTCATCTGTT (NM_001110424.1), GAPDH forward GACCTCCACTACATGGTCTA, GAPDH reverse AAGATGGTGATGGCCTTTC (access No.: NM_001206359.1), PPIA forward GCACTGGTGGCAAGTCCAT, and PPIA reverse AGGACCCGTATGCTTCAGGA (access No.: AY266299), available in GeneBank. Glyceraldehyde 3-phosphate dehydrogenase (GAPDH) and Cyclophylin A (PPIA) were used as normalization controls. Real-Time PCR was performed (7300 Real-Time PCR system; Applied Biosystems, Foster City, CA, USA) as described previously [32]. Each experiment was independently repeated at least three times and the fold change in the expression of each gene was analyzed via the $2^{-\Delta \Delta C t}$ method.

\subsection{SDS-PAGE and Western Blot Analysis}

Gc and Tc were harvested, rinsed twice with PBS, lysed in radioimmunoprecipitation assay buffer (RIPA buffer) with protease inhibitors on ice for $30 \mathrm{~min}$, and then centrifuged $(12,000 \times g)$ for $15 \mathrm{~min}$ at $4{ }^{\circ} \mathrm{C}$. The protein concentration was determined by the Bradford method. Western blot analysis was performed as described previously by Skowronska et al. [32].

\subsection{Immunofluorescence}

Immunofluorescence was performed as previously described [28]. Briefly, cultures were fixed in $4 \%$ paraformaldehyde, rinsed with PBS, permeabilized with $0.2 \%$ saponin $0.01 \mathrm{M}$ PBS for $10 \mathrm{~min}$, and incubated for $30 \mathrm{~min}$ at $37^{\circ} \mathrm{C}$ in PBS containing $10 \%$ normal goat serum (NGS). The slides were then incubated overnight at $4{ }^{\circ} \mathrm{C}$ with an anti-AQP5 antibody (1:200). After washing, coverslips were incubated with Alexa Fluor 488 donkey anti-rabbit IgG conjugated secondary antibodies for one hour. Nuclei were stained with TO-PRO ${ }^{\circledR}-3$ (Invitrogen, Carlsbad, CA, USA). AQP5 localization was detected by fluorescent microscopy (Olympus, Tokyo, Japan).

\subsection{Statistical Analysis}

The data were analyzed by Statistica software (StatSoft Inc., Tulsa, OK, USA). The effect of the treatment was performed by a one-way analysis of variance for repeated measurements, followed by the LSD Fisher post-hoc test. Statistical significances were assigned at $p<0.05$, while non-significant differences indicate $p>0.05$. The data are presented as means \pm S.E.M.

Author Contributions: M.T.S. and A.S. conceived and designed the experiments; D.T. and E.L. analyzed the data; A.S., C.S.P., and B.K. interpreted the results of the experiments; P.M. prepared the figures; M.T.S. and A.S. wrote the paper; all authors read and approved the final manuscript.

Funding: This research was supported by Grants 2013/09/B/NZ9/03129 and 2016/21/B/NZ9/03535 from the National Science Center (NSC). MTS is a recipient of both NCS grants.

Conflicts of Interest: The authors declare no conflicts of interest. 


\section{Abbreviations}

$\begin{array}{ll}\text { AQP5 } & \text { Aquaporin 5 } \\ \text { FSH } & \text { Follicle-stimulating hormone } \\ \text { LH } & \text { Luteinising hormone } \\ \text { PRL } & \text { Prolactin } \\ \text { GH } & \text { Growth hormone } \\ \text { Gc } & \text { Granulosa cells } \\ \text { Tc } & \text { Theca cells } \\ \text { MF } & \text { Medium follicles } \\ \text { LF } & \text { Large follicles } \\ \text { GAPDH } & \text { Glyceraldehyde 3-phosphate dehydrogenase } \\ \text { PPIA } & \text { Cyclophylin A }\end{array}$

\section{References}

1. Preston, G.M.; Carroll, T.P.; Guggino, W.B.; Agre, P. Appearance of water channels in Xenopus oocytes expressing red cell CHIP28 protein. Science 1992, 256, 385-387. [CrossRef] [PubMed]

2. Verkman, A.S. Aquaporins. Curr. Biol. 2013, 23, R52-R55. [CrossRef] [PubMed]

3. Verkman, A.S.; Mitra, A.K. Structure and function of aquaporin water channels. Am. J. Physiol. Renal. Physiol. 2000, 278, 13-28. [CrossRef] [PubMed]

4. Carbrey, J.M.; Agre, P. Discovery of the aquaporins and development of the field. Handb. Exp. Pharm. 2009, 3-28. [CrossRef]

5. Skowronski, M.T.; Lebeck, J.; Rojek, A.; Praetorius, J.; Füchtbauer, E.M.; Frøkiaer, J.; Nielsen, S. AQP7 is localized in capillaries of adipose tissue, cardiac and striated muscle: implications in glycerol metabolism. Am. J. Physiol. Renal. Physiol. 2007, 292, 956-965. [CrossRef] [PubMed]

6. Rojek, A.M.; Skowronski, M.T.; Füchtbauer, E.M.; Füchtbauer, A.C.; Fenton, R.A.; Agre, P.; Frøkiaer, J.; Nielsen, S. Defective glycerol metabolism in aquaporin 9 (AQP9) knockout mice. Proc. Natl. Acad. Sci. USA 2007, 104, 3609-3614. [CrossRef] [PubMed]

7. Bragiel, A.M.; Wang, D.; Pieczonka, T.D.; Shono, M.; Ishikawa, Y. Mechanisms Underlying Activation of $\alpha_{1}$-Adrenergic Receptor-Induced Trafficking of AQP5 in Rat Parotid Acinar Cells under Isotonic or Hypotonic Conditions. Int. J. Mol. Sci. 2017, 17, 1022. [CrossRef]

8. Li, X.; Yu, H.; Koide, S.S. The water channel gene in human uterus. Biochem. Mol. Biol. Int. 1994, 32, 371-377. [PubMed]

9. Escobar, J.; Gormaz, M.; Arduini, A.; Gosens, K.; Martinez, A.; Perales, A.; Escrig, R.; Tormos, E.; Roselló, M.; Orellana, C.; et al. Expression of aquaporins early in human pregnancy. Early Human Develop. 2012, 88, 589-594. [CrossRef]

10. Klein, C.; Troedsson, M.H.; Rutllant, J. Expression of aquaporin water channels in equine endometrium is differentially regulated during the oestrous cycle and early pregnancy. Reprod. Domest. Anim. 2012, 48, 529-537. [CrossRef]

11. Kobayashi, M.; Takahashi, E.; Miyagawa, S.; Watanabe, H.; Iguichi, T. Chromatin immunoprecipitation mediated target identification proved aquaporin 5 is regulated directly by estrogen in the uterus. Genes Cells 2006, 11, 1133-1143. [CrossRef] [PubMed]

12. Lindsay, L.A.; Murphy, C.R. Redistribution of aquaporins 1 and 5 in the rat uterus is dependent on progesterone: a study with light and electron microscopy. Reprod 2006, 131, 369-378. [CrossRef] [PubMed]

13. Richard, C.; Gao, J.; Brown, N.; Reese, J. Aquaporin water channel genes are differentially expressed and regulated by ovarian steroids during the periimplantation period in the mouse. Endocrinology 2003, 144, 1533-1541. [CrossRef] [PubMed]

14. Jablonski, E.M.; McConnell, N.A.; Hughes, F.M., Jr.; Huet-Hudson, Y.M. Estrogen regulation of aquaporins in the mouse uterus: potential roles in uterine water movement. Biol. Reprod. 2003, 69, 1481-1487. [CrossRef] [PubMed]

15. Hildenbrand, A.; Lalitkumar, L.; Nielsen, S.; Genzell-Danilsson, K.; Stavreus- Evers, A. Expression of aquaporin 2 in human endometrium. Fertil. Steril. 2006, 86, 1452-1458. [CrossRef] [PubMed] 
16. Zou, L.B.; Zhang, R.J.; Tan, Y.J.; Ding, G.L.; Shi, S.; Zhang, D.; He, R.H.; Liu, A.X.; Wang, T.T.; Leung, P.C.K.; et al. Identification of Estrogen Response Element in the Aquaporin-2 Gene That Mediates Estrogen-Induced Cell Migration and Invasion in Human Endometrial Carcinoma. J. Clin. Endocrinol. Metab. 2011, 96, 1399-1408. [CrossRef] [PubMed]

17. Ducza, E.; Seres, A.B.; Hajagos-Tóth, J.; Falkay, G.; Gáspár, R. Oxytocin regulates the expression of aquaporin 5 in the late-pregnant rat uterus. Mol. Reprod. Dev. 2014, 81, 524-530. [CrossRef]

18. Csányi, A.; Bóta, J.; Falkay, G.; Gáspár, R.; Ducza, E. The Effects of Female Sexual Hormones on the Expression of Aquaporin 5 in the Late-Pregnant Rat Uterus. Int. J. Mol. Sci. 2016, 17, 1300. [CrossRef]

19. Ducza, E.; Csányi, A.; Gáspár, R. Aquaporins during Pregnancy: Their Function and Significance. Int. J. Mol. Sci. 2017, 18, 2593. [CrossRef]

20. Skowronski, M.T.; Kwon, T.H.; Nielsen, S. Immunolocalization of aquaporin 1, 5 and 9 in the female pig reproductive system. J. Histochem. Cytochem. 2009, 57, 61-67. [CrossRef]

21. Lindsay, L.A.; Murphy, C.R. Aquaporins are upregulated in glandular epithelium at the time of implantation in the rat. J. Mol. Hist. 2007, 38, 87-95. [CrossRef] [PubMed]

22. Thoroddsen, A.; Dahm-Kähler, P.; Lind, A.K.; Weijdegård, B.; Lindenthal, B.; Müller, J.; Brännström, M. The water permeability channels aquaporins 1-4 are differentially expressed in granulosa and theca cells of the preovulatory follicle during precise stages of human ovulation. J. Clin. Endocrinol. Metab. 2011, 96, 1021-1028. [CrossRef] [PubMed]

23. McConnell, N.A.; Yunus, R.S.; Gross, S.A.; Bost, K.L.; Clemens, M.G.; Hughes, F.M., Jr. Water permeability of an ovarian antral follicle is predominantly transcellular and mediated by aquaporins. Endocrinology 2002, 143, 2905-2912. [CrossRef] [PubMed]

24. Starowicz, A.; Grzesiak, M.; Mobasheri, A.; Szoltys, M. Immunolocalization of aquaporin 5 during rat ovarian follicle development and expansion of the preovulatory cumulus oophorus. Acta. Histochem. 2014, 116, 457-465. [CrossRef] [PubMed]

25. Rodgers, R.J.; Irving-Rodgers, H.F. Formation of the ovarian follicular antrum and follicular fluid. Biol. Reprod. 2010, 82, 1021-1029. [CrossRef]

26. Skowronski, M.T. Distribution and quantitative changes in amounts of aquaporin 1,5 and 9 in the pig uterus during the estrous cycle and early pregnancy. Reprod. Biol. Endocrinol. 2010, 8, 109. [CrossRef] [PubMed]

27. Skowronski, M.T.; Skowronska, A.; Nielsen, S. Fluctuation of aquaporin 1, 5, and 9 expression in the pig oviduct during the estrous cycle and early pregnancy. J. Histochem. Cytochem. 2011, 59, 419-427. [CrossRef]

28. Skowronski, M.T.; Mlotkowska, P.; Tanski, D.; Lepiarczyk, E.; Oklinski, M.K.; Nielsen, S.; Skowronska, A. Pituitary Gonadotropins, Prolactin and Growth Hormone Differentially Regulate AQP1 Expression in the Porcine Ovarian Follicular Cells. Int. J. Mol. Sci. 2018, 19, 5. [CrossRef]

29. Britt, K.L.; Findlay, J.K. Estrogen actions in the ovary revisited. J. Endocrinol. 2002, 175, 269-276. [CrossRef]

30. Filicori, M.; Cognigni, G.E.; Gamberini, E.; Parmegiani, L.; Troilo, E.; Roset, B. Efficacy of low-dose human chorionic gonadotropin alone to complete controlled ovarian stimulation. Fertil. Steril. 2005, 84, $394-401$. [CrossRef]

31. Skowronska, A.; Mlotkowska, P.; Okrasa, S.; Nielsen, S.; Skowronski, M.T. Modulatory effects of steroid hormones, oxytocin, arachidonic acid, forskolin and cyclic AMP on the expression of aquaporin 1 and aquaporin 5 in the porcine uterus during placentation. J. Physiol. Pharmacol. 2016, 67, 311-319. [PubMed]

32. Skowronska, A.; Mlotkowska, P.; Majewski, M.; Nielsen, S.; Skowronski, M.T. Expression of aquaporin 1 and 5 and their regulation by ovarian hormones, arachidonic acid, forskolin and cAMP during implantation in pigs. Physiol. Res. 2016, 65, 637-650.

33. Chen, Q.; Peng, H.; Lei, L.; Zhang, Y.; Kuang, H.; Cao, Y.; Shi, Q.X.; Ma, T.; Duan, E. Aquaporin3 is a sperm water channel essential for postcopulatory sperm osmoadaptation and migration. Cell Res. 2011, 21, 922-933. [CrossRef] [PubMed]

34. Sun, X.L.; Zhang, J.; Fan, Y.; Ding, J.H.; Sha, J.H.; Hu, G. Aquaporin-4 deficiency induces subfertility in female mice. Fertil. Steril. 2008, 92, 1736-1743. [CrossRef] [PubMed]

35. Su, W.; Qiao, Y.; Yi, F.; Guan, X.; Zhang, D.; Zhang, S.; Hao, F.; Xiao, Y.; Zhang, H.; Guo, L.; et al. Increased female fertility in aquaporin 8-deficient mice. IUBMB Life 2010, 62, 852-857. [CrossRef] [PubMed]

36. Sha, X.Y.; Xiong, Z.F.; Liu, H.S.; Zheng, Z.; Ma, T.H. Pregnant phenotype in aquaporin 8-deficient mice. Acta Pharmacol. Sin. 2011, 32, 840-844. [CrossRef] [PubMed] 
37. Skowronska, A.; Mlotkowska, P.; Eliszewski, M.; Nielsen, S.; Skowronski, M.T. Expression of aquaporin 1, 5 and 9 in the ovarian follicles of cycling and early pregnant pigs. Physiol. Res. 2015, 64, 237-245. [PubMed]

38. Zhu, C.; Jiang, Z.; Bazer, F.W.; Johnson, G.A.; Burghardt, R.C.; Wu, G. Aquaporins in the female reproductive system of mammals. Front Biosci. (Landmark Ed) 2015, 20, 838-871. [PubMed]

39. Madej, A.; Lang, A.; Brandt, Y.; Kindhal, H.; Madens, M.T.; Einarsson, S. Factors regulating ovarian function in pigs. Domest. Anim. Endocrinol. 2005, 29, 347-361. [CrossRef]

40. Gregoraszczuk, E.L.; Gertler, A.; Bylica, A. Response of porcine theca and granulosa cells to GH during short-term in vitro culture. Anim. Reprod. 2000, 58, 113-125. [CrossRef]

41. Kolodziejczyk, J.; Gertler, A.; Leibovich, H.; Rzasa, J.; Gregoraszczuk, E.L. Synergistic action of growth hormone and insulin-like growth factor I (IGF-I) on proliferation and estradiol secretion in porcine granulosa and theca cells cultured alone or in coculture. Theriogenology 2003, 60, 559-570. [CrossRef]

42. Devesa, J.; Caicedo, D. The Role of Growth Hormone on Ovarian Functioning and Ovarian Angiogenesis. Front Endocrinol. (Lausanne) 2019, 10, 450. [CrossRef] [PubMed]

43. Wang, W.; Li, Q.; Yang, T.; Li, D.; Ding, F.; Sun, H.; Bai, G. RNA interference-mediated silencing of aquaporin (AQP)-5 hinders angiogenesis of colorectal tumor by suppressing the production of vascular endothelial growth factor. Neoplasma 2018, 65, 55-65. [CrossRef] [PubMed]

44. Breves, J.; Inokuchi, M.; Yamaguchi, Y.; Seale, A.; Watanabe, S.; Lerner, D.; Kaneko, T.; Grau, E. Hormonal regulation of aquaporin 3: Opposing actions of prolactin and cortisol in tilapia gill. J. Endocrinol. 2016, 230, 325-337. [CrossRef] [PubMed]

45. Vogel, C.; Marcotte, E.M. Insights into the regulation of protein abundance from proteomic and transcriptomic analyses. Nat. Rev. Genet. 2012, 13, 227-232. [CrossRef] [PubMed]

46. Pelagalli, A.; Squillacioti, C.; Ali, S.; Liguori, G.; Mirabella, N. Cellular distribution of aquaporins in testes of normal and cryptorchid dogs: A preliminary study on dynamic roles. Anim. Reprod. Sci. 2019, 204, 22-30. [CrossRef] [PubMed]

47. Wu, H.; Chen, L.; Zhang, X.; Zhou, Q.; Li, J.M.; Berger, S.; Borok, Z.; Zhou, B.; Xiao, Z.; Yin, H.; et al. Aqp5 is a new transcriptional target of Dot1a and a regulator of Aqp2. PLoS ONE 2013, 8, e53342. [CrossRef] [PubMed]

48. Papadopoulos, M.C.; Saadoun, S. Key roles of aquaporins in tumor biology. Biochim. Biophys Acta. 2015, 1848, 2576-2583. [CrossRef]

49. Madeira, A.; Mósca, A.F.; Moura, T.F.; Soveral, G. Aquaporin-5 is expressed in adipocytes with implications in adipose differentiation. IUBMB Life 2015, 67, 54-60. [CrossRef]

50. Akins, E.L.; Morrissette, M.C. Gross ovarian changes during estrous cycle of swine. Am. J. Vet. Res. 1968, 10, 1953-1957.

51. Stokłosowa, S.; Bahr, J.; Gregoraszczuk, E.L. Some morphological and characteristics of cells of the porcine theca interna in tissue culture. Biol. Reprod. 1978, 19, 712-719. [CrossRef] [PubMed]

52. Nynca, A.; Jablonska, O.; Slomczynska, M.; Petroff, B.K.; Ciereszko, R.E. Effects of phytoestrogen daidzein and estradiol on steroidogenesis and expression of estrogen receptors in porcine luteinized granulosa cells from large follicles. J. Physiol. Pharmacol. 2009, 60, 95-105. [PubMed]

(C) 2019 by the authors. Licensee MDPI, Basel, Switzerland. This article is an open access article distributed under the terms and conditions of the Creative Commons Attribution (CC BY) license (http://creativecommons.org/licenses/by/4.0/). 